\title{
Airborne EM Surveys Applied to Industrial Land- use Legacy Assessments in the UK
}

D. Beamish* (British Geological Survey)

\section{SUMMARY}

Recent high-resolution airborne EM surveys in the UK have identified previously unknown, nongeological, highly conductive

environments in the near-surface. The surveys have covered

a wide range of land-use contexts many of which have several centuries of industrial activities. Two case studies from southern Scotland

are used to demonstrate the magnitude and scale of the high conductivity zones that may be encountered.

The examples indicate that some of the most complex subsurface flow paths

arise in the case of areas associated with coal extraction; here near-surface shafts and adits

connect with shallow worked seams many of which are ancient and lost from modern records. 


\section{Introduction}

A number of airborne geophysical surveys that incorporate frequency-domain EM systems have now been conducted in the UK. The surveys have provided continuity of information at line spacings of between 50 and $200 \mathrm{~m}$ and have encountered a wide range of land-use contexts many of which have centuries of industrial legacy. The mapping of subsurface conductivity has provided a set of discoveries relating to the behaviour of fluid conditions and movements in the near-surface. Some of the most conductive features in the subsurface can be traced for many kilometres and have distinct associations with industrial processes that date back to the middle of the 19'th century. Possibly the most complex subsurface flow paths arise in areas of undermining for coal; here near-surface shafts and adits connect with shallow worked seams many of which are ancient and lost from modern records.

EM data and conductivity models obtained from airborne surveys across some of the coalmining areas of southern Scotland are used to illustrate the extent to which enhanced conductivity variations can be mapped. These legacy environmental effects then provide a starting point for an assessment of the industrial processes that have played their part in influencing near-surface environmental conditions.

\section{Airborne Surveying in the UK}

New high-resolution airborne geophysical coverage of the UK has largely been provided by a fixedwing surveying platform. The system provides magnetic, radiometric and frequency domain electromagnetic survey measurements. Regulatory survey permissions force a variety of flight elevations typically between 54 to $244 \mathrm{~m}$. Routine regional scale flight line spacing is $200 \mathrm{~m}$ but a number of smaller scale infill surveys have used a line spacing of $50 \mathrm{~m}$. The data sets considered here were obtained from an airborne survey across Ayrshire in Southern Scotland in 2004, The aircraft then employed an earlier 2-frequency EM system which used frequencies of 3 and $14 \mathrm{kHz}$. The characteristics of the system together with the more recent 4-frequency enhancement are described by Leväniemi et al. (2009).

\section{The Ardeer Survey}

As an adjunct to a larger scale survey in SW Scotland, the $5 \times 5 \mathrm{~km}$ Ardeer survey was flown using 50 $\mathrm{m} \mathrm{N}$-S flight lines. The site is referred to as the Stevenson site and part of its industrial legacy can be traced back to 1870 with the founding of the first factory by the industrialist Alfred Nobel for the (then) new explosive of dynamite. At its peak, the factory employed nearly 13,000 workers. Small scale, near-surface coal extraction across the site inevitably predates the modern industrial activities. The local/regional councils are required to have a redevelopment plan in place for the entire site. There are a wide range of geophysical responses observed across the site and here we consider the conductivity information observed across a 2 x $1.5 \mathrm{~km}$ area adjacent to the river Garnock.

Figure 1a shows a pre-industrial historical map from 1860 showing locations of 'old shafts' that were identified in the survey. Figure 1b shows a later map from 1897 showing the arrival of a Chlorine works (red polygon) in the vicinity of an existing shaft. The results of the EM survey are shown as two sets of subsurface conductivity contours both exceeding a value of $125 \mathrm{mS} / \mathrm{m}$. The higher frequency $(14 \mathrm{kHz})$ and shallower distribution is shown using darker colours. The centre of the shallower anomaly is clearly displaced to the north of the deeper distribution. In terms of current landuse, the area is best described as derelict land. The plume is highly conductive in relation to the low conductivity of the background coal measures and can be traced over $2 \mathrm{~km}$ beneath the river and railway. The attitudes of the two sets of contours suggests a component of dip to the south. 


\section{Near Surface}
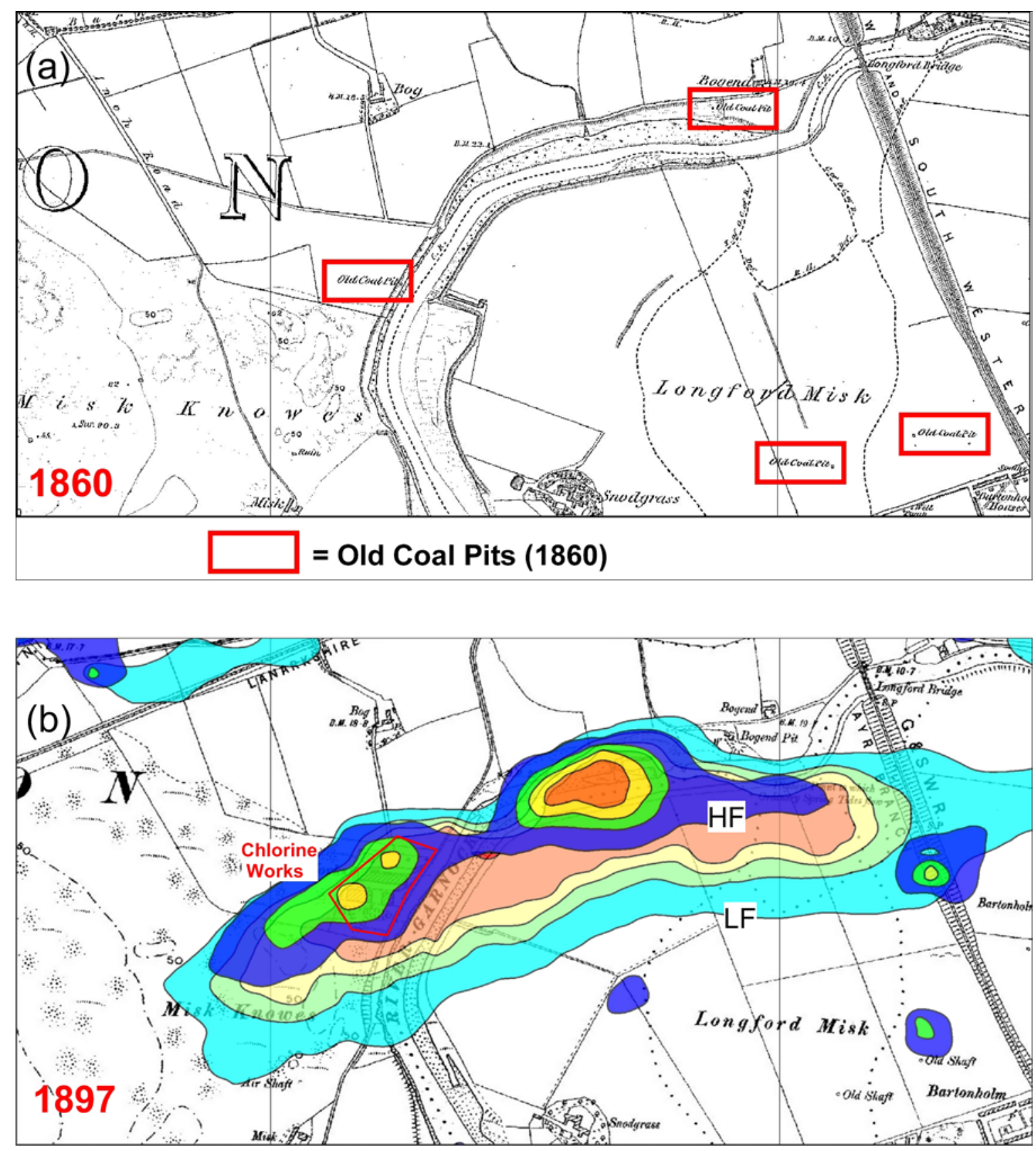

Figure 1. 2 x $15 \mathrm{~km}$ area. (a) Pre-industrial historical map of 1860 showing locations of 'old shafts'. (b) Historical map of 1897 showing arrival of a Chlorine works (red polygon).. Superimposed on map are 2 sets of conductivity contours: Darker blue, high frequency (HF) values $>125 \mathrm{mS} / \mathrm{m}$. Lighter colours, low frequency (LF) conductivity values $>125 \mathrm{mS} / \mathrm{m}$. The contour interval in each case is $100 \mathrm{mS} / \mathrm{m}$.

Although the potential sources of the conductivity can only be surmised some further information could be provided by geochemical sampling from within the plume. In the absence of such information we can use modern geological subsurface information on coal seams to reveal a close correspondence between the arcuate conductivity anomaly and the trace of potential voids arising from worked coal seams. 


\section{Near Surface}

\section{The Muirkirk Valley survey}

Data across the Muirkirk Valley were obtained as part of the same airborne survey across Ayrshire. We here consider an area of 9 x $5 \mathrm{~km}$ across which $50 \mathrm{~m}$ infill surveying was undertaken within the existing $200 \mathrm{~m}$ line spacing. The area contains an industrial hertitage that dates back to 1786 with a tarworks that was developed by MacAdam and an ironworks that predated the arrival of railways. Deep coal mining was a feature of the area until the late $20^{\text {th }}$ century which then saw the development of opencast operations.

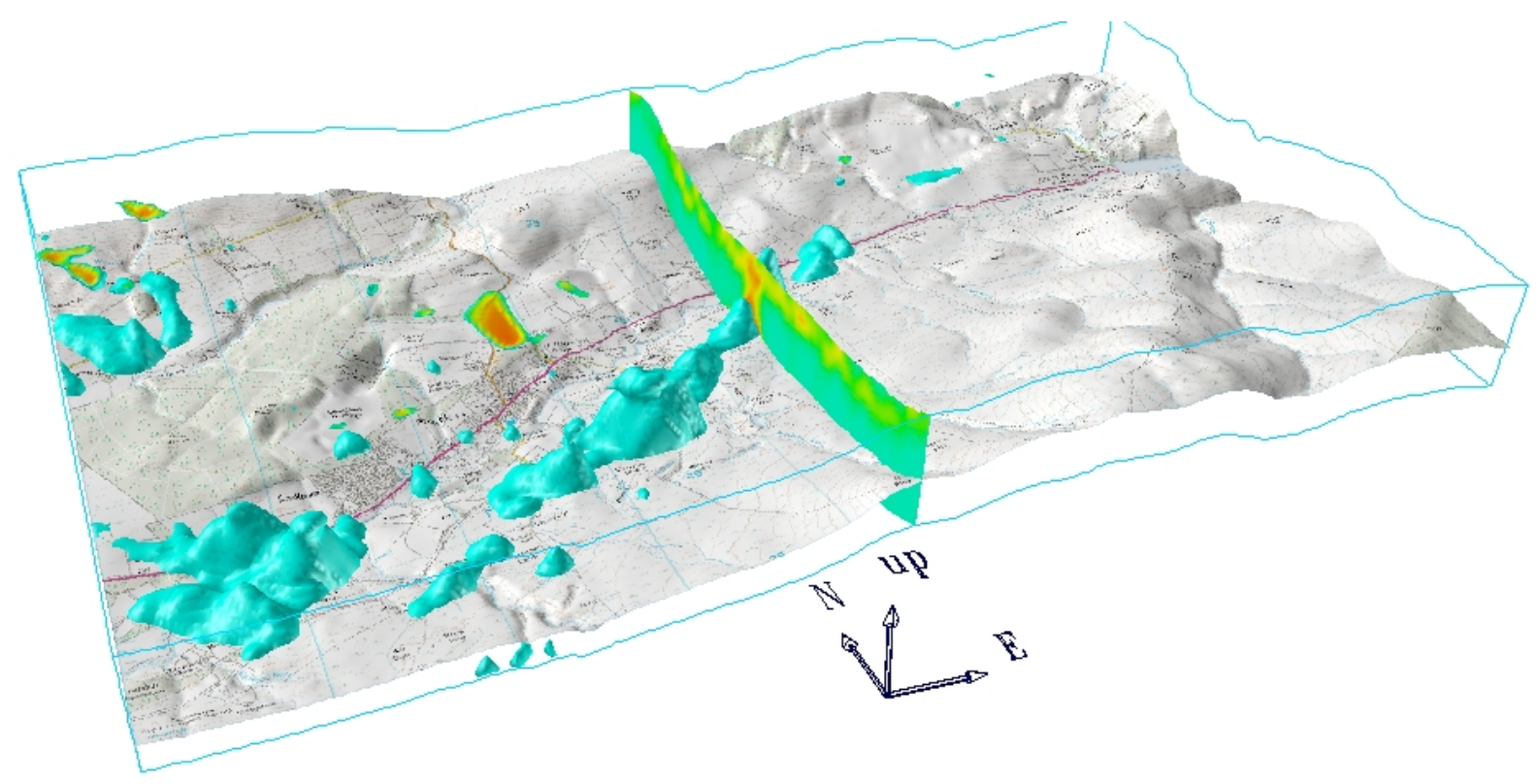

Figure 2. 3D perspective view of the $9 \times 5 \mathrm{~km}$ Muirkirk Valley survey area. The information is displayed draped below the surface of a DTM. The depth extent is $80 \mathrm{~m}$. The map is shown at a depth below surface of $50 \mathrm{~m}$. A subsurface conductivity model volume was obtained by $1 \mathrm{D}$ inversion of the 2 frequency data. The image shows the conductivity isovolume with values $>50 \mathrm{mS} / \mathrm{m}$ together with a central N-S conductivity cross-section through the volume.

The 2-frequency EM survey data were converted to models of subsurface conductivity using a smooth 1D model inversion procedure (Farquharson et al., 2003). The models were then assembled into a continuous voxel-based conductivity volume. The resulting conductivity model across the whole survey area is summarised in Figure 2. The 3D perspective view with a depth extent of $80 \mathrm{~m}$ uses a vertical drape with respect to surface elevation. The image shows elevated conductivity values (> 50 $\mathrm{mS} / \mathrm{m}$ ) as an isovolume with the same colour (cyan). A central N-S cross-section through the volume is also shown for reference. Although a number of conductive, at-surface noise features are evident, the main zones of elevated conductivites are confined to depth. The largest volumes of enhanced conductivities appear as a quasi-continuous zone on the southern slopes of the valley floor that are shown intersecting the cross-section. In order to fully interpret the elevated conductivities it has been necessary to assess historical records of industrial and subsurface coal-mining activities across the area. The known coal seam workings are too deep to account for a simple explanation of the survey results in the upper $80 \mathrm{~m}$. The movement of mine-waters to shallow depths would have to be accounted for by unrecorded mining activities in the shallow strata. 


\section{Conclusions}

Recent high-resolution airborne surveys in the UK have identified a range of previously unknown, non-geological conductive environments in the near-surface. The causes of some of these features, such as those associated with landfills (Beamish, 2003) or at-surface coal mine spoil (Beamish and Klinck, 2006) is anticipated. The examples shown here are less expected and require a wide-ranging assessment of historical surface and subsurface industrial land-use at the sites. As the examples demonstrate, possibly the most complex subsurface flow paths arise in the case of areas of undermining for coal; here near-surface shafts and adits connect with shallow worked seams many of which are ancient and lost from modern records.

\section{Acknowledgement}

This paper is published with the permission of the Executive Director, British Geological Survey (NERC).

\section{References}

Beamish, D. [2003] Characterising landfills from the air. First Break, 21, 67-72.

Beamish, D. and Klinck, B. [2006] Hydrochemical characterization of a coal mine plume detected by an airborne geophysical survey. Geofluids, 6, 82-92.

Farquharson C.G., Oldenburg D.W. and Routh P.S. [2003] Simultaneous 1D inversion of loop-loop electromagnetic data for magnetic susceptibility and electrical conductivity. Geophysics, 68, 18571869.

Leväniemi, H, Beamish, D., Hautaniemi, H., Kurimo, M. Suppala, I., Vironmäki, J., Cuss, D., Lahti, M. and Tartaras, E. [2009] The JAC airborne EM system AEM-05. J. Applied Geophysics, 67, 219233. 